\title{
Development and validation of a risk perception scale of medical help-seeking behavior in Chinese adults
}

\author{
Xiaokang Lyu ${ }^{1,2}$, Ying Liu ${ }^{2}$, Huaran $\mathrm{Yu}^{2}$, Mingdi Mi ${ }^{2}$, Lijun Shang ${ }^{1}$, Yifan Zhong ${ }^{3}$, Dong Xie ${ }^{3}$ \\ ${ }^{1}$ Computational Social Science Laboratory, Nankai University, Tianjin, China; ${ }^{2}$ Department of Social Psychology, Zhou Enlai School of \\ Government, Nankai University, Tianjin, China; ${ }^{3}$ Department of Thoracic Surgery, Shanghai Pulmonary Hospital, School of Medicine, Tongji \\ University, Shanghai, China \\ Contributions: (I) Conception and design: X Lyu, D Xie, Y Zhong; (II) Administrative support: D Xie, Y Zhong, L Shang; (III) Provision of study \\ materials or patients: X Lyu, D Xie; (IV) Collection and assembly of data: Y Liu, H Yu, M Mi; (V) Data analysis and interpretation: Y Liu, H Yu, M \\ Mi; (VI) Manuscript writing: All authors; (VII) Final approval of manuscript: All authors. \\ Correspondence to: Yifan Zhong; Dong Xie. Department of Thoracic Surgery, Shanghai Pulmonary Hospital, Tongji University School of Medicine, \\ Shanghai 200443, China. Email: yifanzhong@126.com; kongduxd@163.com.
}

\begin{abstract}
Background: When people require medical treatment, many risk factors including adverse medical events, economic burdens, and social-psychological consequences may contribute to their hesitation to seek medical help. Therefore, a reliable and valid instrument that can comprehensively assess the risk perception of medical help-seeking behavior among ordinary Chinese adults should be developed.

Methods: The basic dimensions of the scale were determined based on literature review and in-depth interviews with patients. Then, an item pool with 32 items and six dimensions was developed. After the item reduction process based on item and factor analyses, a three-factor, 16-item scale was established. From March 2019, this scale was distributed among 639 healthy adults, outpatients, or inpatients in 20 provinces and municipalities in the mainland of China by convenience sampling. Then, the reliability and validity of the scale were examined.
\end{abstract}

Results: The scale consists of three dimensions (treatment risks, burden risks, and stigma risks) and 16 items. The root-mean-square error of approximation, comparative fit index, and Tucker-Lewis index of this model were $0.069,0.925$, and 0.910 , respectively. The internal consistency reliability of the scale was 0.893 , and the test-retest reliability was 0.784 . The criterion-related validity was $0.720(\mathrm{P}<0.01)$.

Conclusions: The risk perception scale of medical help-seeking behavior is a reliable and valid instrument to measure Chinese adults' perception for potential risks in the process of medical treatment.

Keywords: Risk perception; medical help-seeking behavior; doctor-patient communication; medical risks

Submitted Feb 17, 2020. Accepted for publication Sep 18, 2020.

doi: $10.21037 / \mathrm{atm}-20-1656$

View this article at: http://dx.doi.org/10.21037/atm-20-1656

\section{Introduction}

With the rapid development of medical techniques, a safer and more effective medical service could be provided for people. However, many people still hesitate to seek medical help considering the potential risks throughout the course of medical treatment. For example, some people are afraid of the adverse outcomes from diagnostic or therapeutic procedures (1-3). Some refrain from seeing a doctor because they do not want to be labelled as patients with a particular disease, especially HIV, depression, and other diseases that are highly stigmatized $(4,5)$. In addition, economic burdens and social-psychological pressures play important roles in people's medical help-seeking decisions $(6,7)$. Therefore, it is important to explore the underlying dimensions of people's risk perception for medical help-seeking behavior and further develop a valid tool to measure them.

In the past decades, several instruments for risk perception have been developed. In 1967, Cox (8) first 
proposed the multi-dimension model consisting of economic loss, social outcomes, physical damage, and time loss for risk perception. Thereafter, Jacoby and Kaplan (9) constructed a five-dimension risk perception structure including physical risks, social risks, function risks, psychological risks, and economic risks. In 1975, Peter and Tarpey $\mathrm{Sr}$ (10) added time risks as the sixth dimension in the comparison and analysis of consumers' behaviors. Across different domains, dimensions of risk perception varied from each other, and diverse assessment standards and approaches were adopted (11-14). However, to the best of our knowledge, few studies have attempted to establish reliable tools that can assess the risk perception of medical help-seeking behavior.

Risk perception of help-seeking behavior are highly correlated with the risk perception of illness. Existing studies about illness risk perception mainly focused on patients with specific diseases. For example, the Illness Perception Questionnaire based on patients suffering from seven types of diseases assessed cognitive representations of illness with five subscales: identity, cause, timeline, consequences, and cure control $(15,16)$. In 2015, researchers from the "Effective Communication in Outbreak Management" project developed a standard questionnaire on risk perception of an infectious disease outbreak (17). The dimensions of the scale included knowledge, disease background information, perception of seriousness of the disease, perception of susceptibility to the disease, and self-efficacy of preventive measures. Items regarding the perception of seriousness contained physical discomfort resulting from the disease, treatment outcomes (i.e., death, restriction, pain), and possible psychosocial consequences (i.e., effects on work, family life, and social contacts).

Illness not only damages one's physical and psychological functions but also incurs an economic burden (18-20). In many cases, patients suffered more from economic or socialpsychological pressure than from physical damage. For people living in developing countries such as China, plenty of patients cannot afford medical bills, and many of them still face the risk of health payment-induced poverty (21-23). Therefore, Chinese researchers usually conceptualize illness risk broadly, emphasizing the economic and social dimensions together with the physical loss of a particular disease. In 2014, Fang et al. (24) established a comprehensive risk perception scale for patients with chronic diseases, which comprised three dimensions (physical treatment risks, economic risks, and social-psychological risks) and 12 items. In this scale, physical treatment risks meant worries about damage in physical function and adverse post-treatment consequences, economic risks meant increasing economic burdens rising from higher-than-expected medical cost, and social-psychological risks meant the loss of the sense of identity from relatives and friends when they are labelled as patients. Yan et al. (25) developed a risk perception scale for Chinese cancer patients, which was composed of physical function risks, social-psychological risks, and economic risks.

Although the two Chinese-based illness risk perception scales mentioned above displayed satisfactory reliability and validity, two major drawbacks remained. First, the participants comprised patients diagnosed with certain diseases. In real life, people are often under the threat of diseases and feel anxious before they finally ask for medical help. Therefore, the participants should be extended from patients to all people who require medical help, regardless of whether or not they actually received medical treatment. Studies on the risk perception of medical help-seeking behavior among ordinary people, not limited to a particular disease, are required to provide more information on the pattern of risk perception in the process of help-seeking behavior of the general population. Second, Chinese researchers tend to use the term "medical perception risk" when they are attempting to evaluate comprehensive risks concerning the whole course of medical help seeking. However, the phrasing of "medical risk" is ambiguous in English because medical risks usually imply the negative outcomes of clinical outcomes, not social and psychological burdens.

In the present study, we defined the risks of medical help-seeking behavior as the set of all adverse physical, psychological, social, and economic outcomes if people decide to undergo a diagnostic or therapeutic procedure. The risk perception of help-seeking behavior stems far beyond the time that actual medical treatment is prescribed. In fact, when one considers asking for any kind of medical help, the risk perception process will naturally initiate and interact dynamically with the whole course of medical treatment. Thus, a reliable and valid instrument that can assess the pattern of healthy people and patients perceiving risks during the process of medical help seeking should be developed. We present the following article in accordance with the TRIPOD reporting checklist (available at http:// dx.doi.org/10.21037/atm-20-1656). 


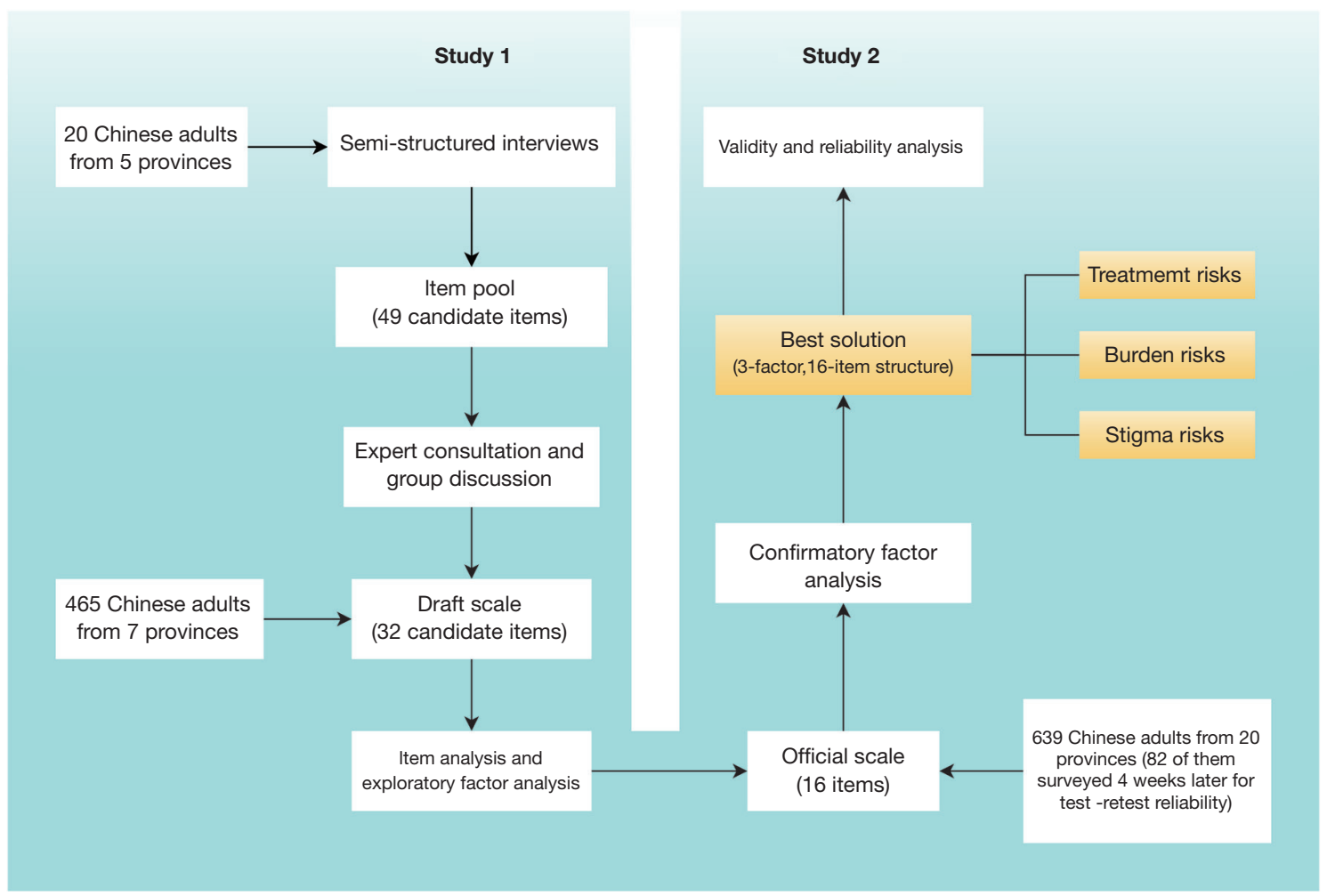

Figure 1 Flowchart of the development of the risk perception scale of medical help-seeking behavior.

\section{Methods}

\section{Study design}

The flowchart of our study is displayed in Figure 1. First, we conducted semi-structured interviews with participants from five different provinces in China to generate the item pool of the risk perception scale of help-seeking behavior (RPSMHB). After expert consultation and group discussion of all authors, a draft scale consisting of 32 items was established for the preliminary test for item selection and dimension exploration. In January 2019, we recruited 465 Chinese adults to finish the draft scale. Subsequently, item and exploratory factor analyses were performed to remove ineligible items and determine the official scale. Finally, based on the official scale, a sample with 639 participants was recruited to validate the psychometric properties of the official scale. The study was conducted in accordance with the Declaration of Helsinki (as revised in 2013). The study was approved by institutional board of Shanghai Pulmonary Hospital and Nankai University and informed consent was taken from all individual participants.

\section{Study 1: Scale development}

\section{Item generation}

We conducted semi-structured interviews with 20 participants who had seen a doctor at least once in the past six months. To ensure independence and representativeness, participants with diverse demographic characteristics (e.g., gender, occupation, age, marital status, residence) were selected. The interviews were conducted one on one by two psychology graduates (Y. L. and H. Y.) in Tianjin, Beijing, Xi'an, Shanghai, and Suzhou. Interviewees were asked to express their worries and concerns when they decided to seek for medical help from six dimensions including economic risks, work risks, social-psychological risks, social support risks, time risks, and treatment risks. A list of 49 candidate items most frequently mentioned by participants formed the first draft of the scale, and each item was measured using a five-point Likert scale ranging from 1 (not worried at all) to 5 (extremely worried).

The draft scale was modified following the advice of an expert consultation team consisting of two associate professors from the psychology department in two 
universities in Beijing and Tianjin and two senior doctors from a general hospital in Shanghai. Items that were difficult to interpret or too ambiguous to understand were deleted to ensure the clarity and interpretability of the scale. The final scale with 32 items was derived based on consensus reached from team discussion (Table 1).

\section{Participants}

A convenience sample with 465 adults who had seen a doctor at least once in the past six months was recruited for preliminary appraisal of the final scale. Participants had a mean age of 37 years. Among them, 69\% were female, $75.3 \%$ lived in urban areas, and $48.6 \%$ were not married. The residences of participants were distributed in seven provinces (Beijing, Tianjin, Shanghai, Shanxi, Jiangsu, Zhejiang, and Xinjiang) in the mainland of China. Details of the demographic information are listed in Table 2.

\section{Item selection and statistical analysis}

We applied three methods for item selection. First, we calculated the total scores of all items for each participant and then assigned those who ranked in the top $27 \%$ into the high-score group and those ranked in the bottom $27 \%$ into the low-score group. For each item, the discrimination between the high-score group and low-score group was compared using Student's $t$-test on their scores. Items with $P$ values more than 0.05 were considered indiscriminative and were suggested to be eliminated.

Second, Pearson's correlation coefficients were calculated to quantify the correlation between the score of each item and total score. Items with $\mathrm{P}$ value more than 0.05 or those whose correlation coefficients were less than 0.4 were also deleted from the item pool.

Third, an exploratory factor analysis (EFA) with promax rotation was performed to further eliminate invalid items. Before EFA, Bartlett's test of sphericity and the KaiserMeyer-Olkin (KMO) measure of sampling adequacy were applied to evaluate factorability. Items with eigenvalue more than 1 were retained. Items with factor loadings less than 0.4 , those with absolute loadings higher than 0.32 on two or more factors, or those with low communalities (less than 0.40 ) were deleted as suggested by the research of Worthington and Whittaker (26).

After item reduction, EFA was conducted again to explore the underlying dimensions of the remaining items. Then, the Cronbach's $\alpha$ coefficients of the whole scale and of each factor were calculated. A P value $<0.05$ was considered to be statistically significant. All above mentioned analyses were performed using SPSS (version 25.0) and Mplus (version 7.0).

\section{Study 2: Reliability and validity test}

\section{Participants}

Participants were excluded if they were involved in Study 1. A total of 639 Chinese adults were recruited from 20 provinces of China, with a mean age of 38 years. Among them, $60.9 \%$ were female, $53.7 \%$ lived in urban areas, and $54.6 \%$ were not married. There were 422 (63.94\%) participants who had seen a doctor at least once in the past 12 months but not in any treatment process at the beginning of the study and 238 (36.06\%) outpatients or inpatients from six hospitals in Shanghai, Anhui, Zhejiang, Tianjin, Beijing, Shaanxi, and Xinjiang. Moreover, 100 participants were invited to complete the RPSMHB again four weeks after the first test to evaluate the test-retest reliability of the scale. Eighteen cases were lost to followup in the second test. The test-retest reliability coefficient was calculated based on the data of the remaining 82 participants. The detailed demographic characteristics of the participants are provided in Table 3.

\section{Measures}

The Chinese version of the Risk Perception Questionnaire for Chronic Patients (supplementary file 2) is a 12 item measure developed by Fang et al. (24) with three dimensions: economic risk, physical and medical risk, and psychosocial risk. The Cronbach's $\alpha$ coefficients of the three factors for this sample are $0.758,0.686$, and 0.608 , respectively. This questionnaire was used to test the criterion validity of the RPSMHB. The items of the criterion validity scale and the RPSMHB were measured by a five-point Likert scale ranging from 1 (not worried at all) to 5 (extremely worried).

\section{Results}

\section{Study 1: Scale development}

\section{Item selection}

No significant difference was observed in items 2, 14, and 25 between the two extreme groups $(\mathrm{P}>0.05)$ (Table 4$)$. Scores of most items showed high correlation with the total score, except items 2, $14(\mathrm{P}>0.05), 10$, and $25(\mathrm{r}<0.2)$. Therefore, items $2,10,14$, and 25 were deleted from the item pool.

Thereafter, we performed a preliminary EFA for 
Table 1 Item pool of risk perception for medical help-seeking behavior

\begin{tabular}{|c|c|c|}
\hline Category & Items & Content \\
\hline \multirow{3}{*}{ Economic/work risks } & 15 & Increasing family economic burden \\
\hline & 9 & High medicine/examination/operation cost \\
\hline & 5 & Unable to make money \\
\hline \multirow[t]{4}{*}{ Social-psychological risks } & 10 & Diseases are more serious than expectation \\
\hline & 6 & Diseases affect my emotions in work \\
\hline & 3 & Diseases affect my emotions in daily life \\
\hline & 16 & Diseases affect my personal image \\
\hline \multirow{4}{*}{ Social support risks } & 17 & Being abandoned by my close friends \\
\hline & 31 & Being despised by others in society \\
\hline & 25 & Nobody can take care of me \\
\hline & 8 & No acquaintances in the hospital \\
\hline \multirow[t]{4}{*}{ Time risks } & 12 & Long treatment time \\
\hline & 19 & Long recovery time \\
\hline & 30 & Cumbersome process of reimbursement \\
\hline & 7 & Ongoing works are delayed \\
\hline \multirow{3}{*}{ Medical process risks } & 13 & Obsolete medical equipment \\
\hline & 21 & Negative attitude of medical staff \\
\hline & 14 & Doctor-to-patient disputes \\
\hline \multirow[t]{5}{*}{ Treatment risks } & 22 & Unreasonable treatment methods \\
\hline & 24 & Side effects of medicines/examinations/operations \\
\hline & 26 & Medical accidents \\
\hline & 18 & Post-treatment complications \\
\hline & 4 & Misdiagnosis \\
\hline
\end{tabular}

the remaining 28 items after deleting items 2, 10, 14, and 25 from the item pool. Bartlett's test of sphericity was $7,083.667$, and the KMO measure was 0.938 , both indicating good factorability. Five factors were extracted with eigenvalue more than 1 , and the accumulative variance contribution accounted to $61.252 \%$. However, items 1,3 , 
Page 6 of 11

Table 2 Demographic characteristics of participants in study 1 $(\mathrm{n}=465)$

\begin{tabular}{|c|c|}
\hline Characteristics & $\mathrm{n}(\%)$ \\
\hline \multicolumn{2}{|l|}{ Age } \\
\hline$\leq 30$ & 149 (32.0) \\
\hline $31-40$ & $170(36.6)$ \\
\hline $41-50$ & $63(13.5)$ \\
\hline $51-60$ & $73(15.7)$ \\
\hline$>60$ & $10(2.2)$ \\
\hline \multicolumn{2}{|l|}{ Gender } \\
\hline Male & $143(30.8)$ \\
\hline Female & $322(69.2)$ \\
\hline \multicolumn{2}{|l|}{ Education } \\
\hline Junior high school or lower & $14(3.0)$ \\
\hline Senior high school or Technical secondary school & $40(8.6)$ \\
\hline Junior college or vocational and technical college & $33(7.1)$ \\
\hline University or higher & $378(81.3)$ \\
\hline \multicolumn{2}{|l|}{ Registered permanent residence } \\
\hline Rural & $115(24.7)$ \\
\hline Urban & $350(75.3)$ \\
\hline \multicolumn{2}{|l|}{ Marital status } \\
\hline Married & $230(49.5)$ \\
\hline Not married & $226(48.6)$ \\
\hline Others & $9(1.9)$ \\
\hline \multicolumn{2}{|l|}{ Number of children } \\
\hline 0 & $272(58.5)$ \\
\hline 1 & 139 (29.9) \\
\hline 2 & $51(11.0)$ \\
\hline$\geq 3$ & $3(0.6)$ \\
\hline
\end{tabular}

$4,8,12$, and 19 were deleted because their communality scores were lower than 0.4 or their factor loadings were less than 0.4 . Items 5, 6, 15, 18, 21, and 30 were removed because their absolute loadings were higher than 0.32 on two or more factors. Thus, 16 items were deleted from the initial scale, and the remaining 16 items were retained.

\section{EFA and factor solution}

For the remaining 16 items, further EFA was implemented with the same procedure mentioned above, which revealed

\section{Lyu et al. Risk perception scale of medical help-seeking behavior}

Table 3 Demographic characteristics of participants in study $2(n=639)$

\begin{tabular}{|c|c|}
\hline Characteristics & n (\%) \\
\hline \multicolumn{2}{|l|}{ Age } \\
\hline$\leq 30$ & $152(23.8)$ \\
\hline $31-40$ & $288(45.1)$ \\
\hline $41-50$ & $124(19.4)$ \\
\hline $51-60$ & $58(9.1)$ \\
\hline$>60$ & $17(2.7)$ \\
\hline \multicolumn{2}{|l|}{ Gender } \\
\hline Male & $250(39.1)$ \\
\hline Female & $389(60.9)$ \\
\hline \multicolumn{2}{|l|}{ Education } \\
\hline Junior high school or lower & $3(0.5)$ \\
\hline Senior high school or Technical secondary school & $94(14.7)$ \\
\hline Junior college or vocational and technical college & $101(15.8)$ \\
\hline University or higher & $441(69.0)$ \\
\hline \multicolumn{2}{|l|}{ Registered permanent residence } \\
\hline Rural & $76(11.9)$ \\
\hline Urban & $343(53.7)$ \\
\hline Undeclared & $220(34.4)$ \\
\hline \multicolumn{2}{|l|}{ Marital status } \\
\hline Married & $64(10.0)$ \\
\hline Not married & $349(54.6)$ \\
\hline Others & $6(0.9)$ \\
\hline Unknown & $220(34.4)$ \\
\hline \multicolumn{2}{|l|}{ Number of children } \\
\hline 0 & $315(49.3)$ \\
\hline 1 & 254 (39.7) \\
\hline 2 & $69(10.8)$ \\
\hline$\geq 3$ & $1(0.2)$ \\
\hline
\end{tabular}

the same three-factor structure, and the accumulative variance contribution accounted to $64.146 \%$ (Table 5). Factor 1 consisted of items 13, 20, 22, 23, 24, 26, 27, and 28. Factor 2 was composed of items 7, 9, 11, 29, and 32 . Factor 3 contained items 16, 17, and 31 .

\section{Internal consistency}

The Cronbach's $\alpha$ coefficient of the whole 16-item scale was 
Table 4 Student's $t$-test for each item between high-score group and low-score group

\begin{tabular}{|c|c|c|c|}
\hline Items & $\begin{array}{l}\text { Low-score group } \\
\quad(\text { mean } \pm \text { SD })\end{array}$ & $\begin{array}{l}\text { High-score group } \\
\quad(\text { mean } \pm \text { SD) }\end{array}$ & $P$ value \\
\hline 1 & $2.60 \pm 1.29$ & $4.04 \pm 1.11$ & $<0.001$ \\
\hline 2 & $2.91 \pm 1.45$ & $3.06 \pm 1.41$ & 0.404 \\
\hline 3 & $2.79 \pm 1.26$ & $4.29 \pm 0.92$ & $<0.001$ \\
\hline 4 & $2.24 \pm 1.31$ & $4.71 \pm 0.63$ & $<0.001$ \\
\hline 5 & $2.43 \pm 1.17$ & $4.38 \pm 0.82$ & $<0.001$ \\
\hline 6 & $2.66 \pm 1.25$ & $4.41 \pm 0.72$ & $<0.001$ \\
\hline 7 & $3.07 \pm 1.36$ & $4.44 \pm 0.75$ & $<0.001$ \\
\hline 8 & $2.38 \pm 1.07$ & $4.21 \pm 0.90$ & $<0.001$ \\
\hline 9 & $3.50 \pm 1.10$ & $4.75 \pm 0.65$ & $<0.001$ \\
\hline 10 & $4.02 \pm 1.02$ & $4.35 \pm 1.41$ & 0.036 \\
\hline 11 & $3.40 \pm 1.15$ & $4.83 \pm 0.49$ & $<0.001$ \\
\hline 12 & $3.60 \pm 1.13$ & $4.81 \pm 0.52$ & $<0.001$ \\
\hline 13 & $2.75 \pm 1.21$ & $4.56 \pm 0.72$ & $<0.001$ \\
\hline 14 & $2.87 \pm 1.43$ & $3.22 \pm 1.61$ & 0.070 \\
\hline 15 & $3.25 \pm 1.27$ & $4.94 \pm 0.23$ & $<0.001$ \\
\hline 16 & $2.15 \pm 1.10$ & $4.02 \pm 1.01$ & $<0.001$ \\
\hline 17 & $1.79 \pm 0.95$ & $3.60 \pm 1.17$ & $<0.001$ \\
\hline 18 & $3.12 \pm 1.20$ & $4.78 \pm 0.44$ & $<0.001$ \\
\hline 19 & $2.98 \pm 1.15$ & $4.63 \pm 0.70$ & $<0.001$ \\
\hline 20 & $2.93 \pm 1.20$ & $4.74 \pm 0.52$ & $<0.001$ \\
\hline 21 & $2.25 \pm 1.07$ & $4.33 \pm 0.76$ & $<0.001$ \\
\hline 22 & $2.92 \pm 1.20$ & $4.73 \pm 0.48$ & $<0.001$ \\
\hline 23 & $3.00 \pm 1.21$ & $4.70 \pm 0.56$ & $<0.001$ \\
\hline 24 & $3.16 \pm 1.13$ & $4.76 \pm 0.43$ & $<0.001$ \\
\hline 25 & $2.92 \pm 1.50$ & $3.25 \pm 1.49$ & 0.077 \\
\hline 26 & $3.10 \pm 1.24$ & $4.71 \pm 0.49$ & $<0.001$ \\
\hline 27 & $3.00 \pm 1.25$ & $4.77 \pm 0.52$ & $<0.001$ \\
\hline 28 & $2.65 \pm 1.22$ & $4.67 \pm 0.61$ & $<0.001$ \\
\hline 29 & $2.73 \pm 1.18$ & $4.57 \pm 0.61$ & $<0.001$ \\
\hline 30 & $3.02 \pm 1.30$ & $4.51 \pm 0.75$ & $<0.001$ \\
\hline 31 & $1.69 \pm 0.82$ & $3.58 \pm 1.18$ & $<0.001$ \\
\hline 32 & $2.91 \pm 1.33$ & $4.76 \pm 0.53$ & $<0.001$ \\
\hline
\end{tabular}

$\mathrm{SD}$, standard deviation.
0.941, and that of the three factors ranged between 0.732 to 0.932 , which indicated satisfactory internal consistency among items of the scale.

\section{Summary}

Through the item reduction process based on item analysis and EFA, we removed 12 items from the initial item pool and finally developed a three-factor, 16-item RPSMHB (supplementary file 1). Items in factor 1 measured the perception for efficiency and safety of medical treatment to be administered. As such, factor 1 was described as treatment risks. Factor 2 focused on the economic, workplace, and family pressure that a person might suffer during the process of medical help seeking and was summarized as burden risks. Factor 3 evaluated the social stigma perception arising from a particular disease and was named as stigma risks. The Cronbach's $\alpha$ coefficient of the preliminary scale supported the satisfactory internal consistency among the items.

\section{Study 2: Reliability and validity test}

\section{Reliability}

\section{Internal consistency reliability}

The Cronbach's $\alpha$ coefficient of the RPSMHB was 0.893, and those of the treatment, burden, and stigma risk factors were $0.890,0.773$, and 0.722 , respectively.

\section{Test-retest reliability}

The test-retest reliability coefficient for the RPSMHB was 0.784 , and those for the dimensions of treatment risks, burden risks, and stigma risks were $0.710,0.852$, and 0.603 , respectively.

\section{Validity \\ Construct validity}

Bartlett's test of sphericity and the KMO value were $4,124.589$ and 0.914 , respectively, which verified the suitability of RPSMHB for further factor analysis. Confirmatory factor analysis (CFA) was performed to confirm the three-factor structure of RPSMHB, revealing the acceptable fit of this three-factor model $\left(\chi^{2}=406.65\right.$, $\left.\mathrm{df}=101, \chi^{2} / \mathrm{df}=4.0<5\right)$. The root-mean-square error of approximation (RMSEA), comparative fit index (CFI), and Tucker-Lewis index (TLI) of this model were $0.069(<0.08)$, 0.925 , and $0.910(>0.9)$, respectively. All the above indexes 
Table 5 Exploratory factor analysis of the official scale (16 items)

\begin{tabular}{|c|c|c|c|c|c|}
\hline \multicolumn{2}{|l|}{ Factor 1 (treatment risks) } & \multicolumn{2}{|c|}{ Factor 2 (burden risks) } & \multicolumn{2}{|c|}{ Factor 3 (stigma risks) } \\
\hline 23 & 0.899 & 9 & 0.869 & 17 & 0.946 \\
\hline 26 & 0.811 & 29 & 0.706 & 16 & 0.780 \\
\hline 20 & 0.799 & 32 & 0.661 & 31 & 0.702 \\
\hline 22 & 0.777 & 7 & 0.529 & & \\
\hline 24 & 0.766 & & & & \\
\hline 28 & 0.752 & & & & \\
\hline 13 & 0.630 & & & & \\
\hline Cumulative variance contribution (\%) & 44.470 & & 54.056 & & 61.146 \\
\hline
\end{tabular}

Here, items with factor loading less than 0.40 on any factor and those with factor loading at 0.32 or above on two or more factors were deleted and not presented in this table.

Table 6 Confirmatory factor analysis results of the risk perception scale based on different factor structures

\begin{tabular}{|c|c|c|c|c|c|c|c|c|}
\hline Model & $\chi^{2}$ & $d f$ & $\chi^{2} / \mathrm{df}$ & AIC & $\mathrm{BIC}$ & TLI & CFI & RMSEA \\
\hline $2 \mathrm{~A}$ & 670.65 & 103 & 6.51 & $30,099.67$ & $30,318.20$ & 0.837 & 0.860 & 0.093 \\
\hline $2 \mathrm{~B}$ & 686.118 & 103 & 6.66 & $30,115.14$ & $30,333.67$ & 0.832 & 0.856 & 0.094 \\
\hline $2 \mathrm{C}$ & 720.981 & 103 & 7.00 & $30,150.00$ & $30,368.54$ & 0.822 & 0.847 & 0.097 \\
\hline
\end{tabular}

Numbers listed in the column Model indicated the numbers of factors in the model. Two-factor model had three possible combinations. The model $2 \mathrm{~A}$ consisted of factor 1 (treatment risks in study 1 ) and factor 2 (combination of burden risk factors and stigma risks in study 1 ). The model $2 \mathrm{~B}$ consisted of factor 1 (combination of treatment risks and burden risks in study 1) and factor 2 (stigma risks in study 1 ). The model $2 \mathrm{C}$ consisted of factor 1 (combination of treatment risks and stigma risks in study 1) and factor 2 (burden risks in study 1 ). AIC, Akaike information criterion; BIC, Bayesian information criterion; TLI, Tucker-Lewis index; CFI, comparative fit index; RMSEA, root-mean-square error of approximation.

supported the adequacy of the three-factor model.

We also examined a one-factor solution $\left(\chi^{2}=975.06, \mathrm{df}\right.$ $=104, \chi^{2} / \mathrm{df}=9.38, \mathrm{RMSEA}=0.114, \mathrm{CFI}=0.785, \mathrm{TLI}=0.752$ ) and all possible two-factor solutions (Table 6 ) and found that the one- and two-factor solutions could not achieve an adequate fit to the data $\left(\chi^{2} / \mathrm{df}>5\right.$, RMSEA $>0.09$, CFI $<0.9$, TLI $<0.9$ ), which further confirmed the performance of the three-factor solution.

\section{Criterion validity}

Pearson's correlation coefficient between the criterion validity scale and the RPSMHB was $0.720(\mathrm{P}<0.01)$.
Pearson's correlation coefficients between dimensions of the two scale are presented in detail in Table 7.

\section{Summary}

High internal consistency was identified for the RPSMHB or dimensions of the scale. The test-retest reliability coefficients of each dimension ranged from 0.603 to 0.852 , indicating its adequate consistency in the four-week retest. In addition, the performance of the three-factor RPSMHB was confirmed by the satisfactory CFA results and the acceptable criterion validity. In summary, our developed 
Table 7 Pearson's correlation coefficients between the risk perception scale of medical help-seeking behavior and criterion validity scale

\begin{tabular}{|c|c|c|c|c|}
\hline Variable & $\frac{\text { Scale }}{\text { Criterion validity scale }}$ & \multicolumn{3}{|c|}{ Dimensions } \\
\hline \multicolumn{5}{|l|}{ Scale } \\
\hline RPSMHB & 0.720 & 0.621 & 0.548 & 0.462 \\
\hline \multicolumn{5}{|l|}{ Dimensions } \\
\hline Burden risks & 0.504 & 0.271 & 0.638 & 0.299 \\
\hline Stigma risks & 0.292 & 0.223 & 0.111 & 0.346 \\
\hline
\end{tabular}

RPSMHB, risk perception scale of medical help seeking.

RPSMHB showed reliable psychometric properties.

\section{Discussion}

To our knowledge, this study is the first to develop a risk perception scale on medical help-seeking behavior within the context of Chinese culture. We developed a novel comprehensive risk perception scale on seeking medical help based on Chinese adults, which achieved satisfactory psychometric properties and was applicable either for ordinary people without any specific disease or for patients who have been administered with a particular treatment. Therefore, the RPSMHB provides a convenient and efficient evaluation for the overall risk that people would encounter. The application of the scale is beneficial for health authorities and medical institutions to understand people's cognition of the potential risks when they decide to ask for medical help. On this basis, effective measures to avoid medical disputes and strategies to counter barriers of medical help seeking could be adopted.

Compared with the popular yet narrowly defined concept of medical risk, the risk of medical help-seeking behavior is usually conceived more broadly. Previous works had shown that people would always try to make a balance among all the risk factors before they finally make a decision to seek for medical help, including medical risks during the process of treatment, economic risks, workplace and family burdens, and social-psychological losses. Some of these factors are also known as barriers to medical help seeking (27-29). However, previous studies mainly focused on the investigation of potential barriers for specific groups, such as African Americans, refugees, sexual and gender minority members, mental illness sufferers, and other disadvantaged groups (30-34). A universal tool to assess all cognitive barriers for ordinary people still remains to be developed. In addition, the so-called "barriers" are not necessarily true in that higher perception level of risk perception may prompt individuals to seek medical help immediately and actively. In other words, the risk perception on potential treatments may play as drivers or barriers in people's medical helpseeking behaviors, depending on the nature of risks and one's personality traits $(35,36)$. Therefore, a reliable and valid instrument that can objectively assess the risk perception of medical help-seeking behavior needs to be developed.

We also found that several Chinese researchers used the term "medical risk" vaguely to encompass all the risks mentioned in our study (24). Although medical risk may contain diverse sources of risks pertaining to medical services within the Chinese context, it remains peculiar for most international users and medical professionals. We recommend to use the risks of medical help-seeking behavior instead of medical risks to draw a clear distinction between the narrow cognition of medical risks within the medical context and all-encompassing notions in everyday life. In this way, potential users of this scale all around the world would easily understand and use this scale.

Despite the high reliability and validity of the RPSMHB, our study still had some limitations. First, the study population in our research lacked representativeness for the whole Chinese population because most participants $(97.30 \%)$ were less than 60 years old. The elderly constitute a major force in the Chinese medical service market, and they may have different patterns of risk perception due to their age and specific medical service demands. Future studies should recruit more elderly participants with diverse medical histories to uncover their unique risk perception characteristics. Moreover, we only demonstrated three dimensions, including treatment risks, burden 


\section{Page 10 of 11}

risks, and stigma risks, in the risk perception of medical help-seeking behavior. A previous study reported a sixdimension structure of medical risk perception for Chinese patients (37). Why the structure of risk perception differs so obviously remains to be explained. Future studies with larger samples should compare the performance of different scales to provide a possible explanation for the structural differences of the risk perception between medical risks and medical help-seeking behaviors.

\section{Conclusions}

The RPSMHB developed in this study is a reliable and valid instrument to measure the risk perception level for Chinese adults who decide to seek medical help.

\section{Acknowledgments}

We gratefully acknowledge three graduate students (He Jiang, Huijuan Zhang, Ji Wang) for their work during the scale development and data collection. We would like to thank all participants for their answers to and valuable comments on the scale.

Funding: This work was supported by the MOE (Ministry of Education in China) Liberal arts and Social Sciences Youth Foundation (19YJC840030) and Philosophical and Social Science Program of Tianjin, China (TJJX18-001).

\section{Footnote}

Reporting Checklist: The authors have completed the TRIPOD reporting checklist. Available at http://dx.doi. org/10.21037/atm-20-1656

Data Sharing Statement: Available at http://dx.doi. org/10.21037/atm-20-1656

Conflicts of Interest: All authors have completed the ICMJE uniform disclosure form (available at http://dx.doi. org/10.21037/atm-20-1656). The authors have no conflicts of interest to declare.

Ethical Statement: The authors are accountable for all aspects of the work in ensuring that questions related to the accuracy or integrity of any part of the work are appropriately investigated and resolved. The study was conducted in accordance with the Declaration of Helsinki (as revised in 2013). The study was approved by institutional

\section{Lyu et al. Risk perception scale of medical help-seeking behavior}

board of Shanghai Pulmonary Hospital (L20-333Y) and Nankai University (L20-475C) and informed consent was taken from all individual participants.

Open Access Statement: This is an Open Access article distributed in accordance with the Creative Commons Attribution-NonCommercial-NoDerivs 4.0 International License (CC BY-NC-ND 4.0), which permits the noncommercial replication and distribution of the article with the strict proviso that no changes or edits are made and the original work is properly cited (including links to both the formal publication through the relevant DOI and the license). See: https://creativecommons.org/licenses/by-nc-nd/4.0/.

\section{References}

1. Al Qadire M. Awareness of Cancer Signs and Barriers to Help Seeking: a National Survey. J Cancer Educ 2018;33:1206-12.

2. Medina-Perucha L, Yousaf O, Hunter MS, et al. Barriers to medical help-seeking among older men with prostate cancer. J Psychosoc Oncol 2017;35:531-43.

3. Mueller J, Jay C, Harper S, et al. The Role of Web-Based Health Information in Help-Seeking Behavior Prior to a Diagnosis of Lung Cancer: A Mixed-Methods Study. J Med Internet Res 2017;19:e189.

4. Dong X, Yang J, Peng L, et al. HIV-related stigma and discrimination amongst healthcare providers in Guangzhou, China. BMC Public Health 2018;18:738.

5. Lyons B, Dolezal L. Shame, stigma and medicine. Med Humanit 2017;43:208.

6. Wang C, Wang C, Liu M, et al. Temporal and spatial trends of ischemic heart disease burden in Chinese and subgroup populations from 1990 to 2016: socioeconomical data from the 2016 global burden of disease study. BMC Cardiovasc Dis 2020;20.

7. Xu J, Wang J, Wimo A, et al. The economic burden of dementia in China, 1990-2030: implications for health policy. Bull World Health Organ 2017;95:18-26.

8. Cox DF. Risk handling in consumer behavior: An intensive study of two cases. Boston: Harvard University Press 1967:34-81.

9. Jacoby J, Kaplan L. The components of perceived risk. Adv Consumer Res 1972;3:382-93.

10. Peter JP, Tarpey Sr LX. A comparative analysis of three consumer decision strategies. J Consumer Res 1975;2:29-37.

11. Sowby FD. Radiation and other risks. Health Physics 
1965;11:879-87.

12. Starr C. Social benefit versus technological risk. Science 1969:165:1232-8.

13. Sjöberg L. Factors in risk perception. Risk Analysis 2000;20:1-12.

14. Visschers VH, Siegrist M. Exploring the triangular relationship between trust, affect, and risk perception: A review of the literature. Risk Management 2008;10:156-67.

15. Broadbent E, Petrie KJ, Main J, et al. The brief illness perception questionnaire. J Psychosom Res 2006;60:631-7.

16. Weinman J, Petrie KJ, Moss-morris R, et al. The illness perception questionnaire: A new method for assessing the cognitive representation of illness. Psychol Health 1996;11:431-45.

17. Wulff A, Ahmad A, Cloes R, et al. Effective Communication in Outbreak Management - Experiences and Suggestions by European Public Health Experts. Das Gesundheitswesen 2015;77:A328.

18. Greenberg PE, Kessler RC, Birnbaum HG, et al. The economic burden of depression in the United States: how did it change between 1990 and 2000? J Clin Psychiatry 2003;64:1465-75.

19. Béjean S, Sultan-Taïeb H. Modeling the economic burden of diseases imputable to stress at work. Eur J Health Econ 2005;6:16-23.

20. Rajsic S, Gothe H, Borba H, et al. Economic burden of stroke: a systematic review on post-stroke care. Eur J Health Econ 2019;20:107-34.

21. Meng Q, Fang H, Liu X, et al. Consolidating the social health insurance schemes in China: towards an equitable and efficient health system. Lancet 2015;386:1484-92.

22. He AJ, Wu S. Towards Universal Health Coverage via Social Health Insurance in China: Systemic Fragmentation, Reform Imperatives, and Policy Alternatives. Appl Health Econ Health Policy 2017;15:707-16.

23. Chen C, Pan J. The effect of the health poverty alleviation project on financial risk protection for rural residents: evidence from Chishui City, China. Int J Equity Health 2019;18:79.

24. Fang L, Ren P, Zhang Y, et al. Primary development of risk perception questionnaire for chronic patients. China J Health Psychol 2014;22:1865-7.

25. Yan X, Zhao S, Sun B, et al. Cancer patients' perception of medical risk and it's influence on clinical decision making. Med Philosophy(B) 2014;35:31-3.

26. Worthington RL, Whittaker TA. Scale Development Research: A Content Analysis and Recommendations for
Best Practices. Counseling Psychologist 2006;34:806-38.

27. Carter-Harris L. Lung cancer stigma as a barrier to medical help-seeking behavior: Practice implications. J Am Assoc Nurse Pract 2015;27:240-5.

28. Gandy M, Karin E, Fogliati VJ, et al. Emotional and cognitive difficulties, help-seeking, and barriers to treatment in neurological disorders. Rehabil Psychol 2018;63:563-74.

29. Keizer E, Christensen MB, Carlsen AH, et al. Factors related to out-of-hours help-seeking for acute health problems: a survey study using case scenarios. BMC Public Health 2019;19:33.

30. Griffith DM, Allen JO, Gunter K. Social and Cultural Factors Influence African American Men's Medical Help Seeking. Res Social Work Practice 2011;21:337-47.

31. Yousaf O, Grunfeld EA, Hunter MS. A systematic review of the factors associated with delays in medical and psychological help-seeking among men. Health Psychol Rev 2015;9:264-76.

32. Mansfield AK, Addis ME, Courtenay W. Measurement of Men's Help Seeking: Development and Evaluation of the Barriers to Help Seeking Scale. Psychol Men Masculinity 2005;6:95-108.

33. Calton JM, Cattaneo LB, Gebhard KT. Barriers to Help Seeking for Lesbian, Gay, Bisexual, Transgender, and Queer Survivors of Intimate Partner Violence. Trauma Violence Abuse 2016;17:585-600.

34. Byrow Y, Pajak R, Specker P, et al. Perceptions of mental health and perceived barriers to mental health help-seeking amongst refugees: A systematic review. Clin Psychol Rev 2020;75:101812.

35. Tinetti A, Weir N, Tangyotkajohn U, et al. Help-seeking behaviour for pelvic floor dysfunction in women over 55 : drivers and barriers. Int Urogynecol J 2018;29:1645-53.

36. Hinchliff S, Carvalheira AA, Stulhofer A, et al. Seeking help for sexual difficulties: findings from a study with older adults in four European countries. Eur J Ageing 2019;17:185-95.

37. Zeng Z, Xiang G, Chen X. Review on the Study of Medical Risk Perception. The Chinese Health Service Management 2018;35:478-80.

Cite this article as: Lyu X, Liu Y, Yu H, Mi M, Shang L, Zhong Y, Xie D. Development and validation of a risk perception scale of medical help-seeking behavior in Chinese adults. Ann Transl Med 2020;8(21):1352. doi: 10.21037/atm$20-1656$ 